\title{
Short Communication: Effect of Number of Extractions on Percentage of Long-Chain Fatty Acids from Fresh Alfalfa ${ }^{1}$
}

\author{
C. V. D. M. Ribeiro and M. L. Eastridge ${ }^{2}$ \\ Department of Animal Sciences, The Ohio State University, Columbus 43210
}

\begin{abstract}
Accurate determination of fatty acids in fresh forage is very important when studying biohydrogenation. Fatty acids from fresh alfalfa were extracted by hexane:isopropanol (H:IP, 3:2 vol/vol) in 3 sequential extractions. The percentage and profile of fatty acids from each of the 3 extractions were evaluated by a randomized complete block design with repeated measures in space. Samples of fresh alfalfa were randomly harvested and immediately submerged in liquid nitrogen. For the first extraction, approximately $5 \mathrm{~g}$ of the frozen alfalfa was mixed with $18 \mathrm{~mL}$ of H:IP per gram of material. Samples were then centrifuged and the supernatant was collected. The second and third extractions were done by adding $\mathrm{H}: \mathrm{IP}$ to the pellet $(3 \mathrm{~mL} / \mathrm{g}$ of the original sample weight), mixing for $2 \mathrm{~min}$, and then centrifuging. Samples were submerged in H:IP and stored in the dark at $8^{\circ} \mathrm{C}$ at all times. The solvent from each extraction was partially evaporated and the fatty acids methylated by methanolic HCl. Repeated extractions increased the percentage of total fatty acids recovered from the samples. The concentration of fatty acids in the alfalfa after 3 extractions was $4.0 \%$. The first, second, and third extractions resulted in 92.7, 4.8, and $2.6 \%$ of the total fatty acids extracted, respectively. There was no effect of extraction on the proportion of $16: 0,18: 0,18: 1$, and 18:2 fatty acids. However, the proportion of 18:3 in the extract decreased from the first to the second extraction and the ratio of saturated to unsaturated fatty acid increased from the first to the second extraction. The results of this experiment revealed that the profile of fatty acids can vary with the number of extractions performed. The higher amount of 18:3 in the first extraction may reflect the higher proportion of linolenic acid in the more easily extracted plant fractions.
\end{abstract}

Key words: fresh alfalfa, extraction, fatty acids

An accurate assessment of the profile and percentage total fatty acids (FA) from fresh forage is crucial when

\footnotetext{
Received November 16, 2005.

Accepted March 21, 2006.

${ }^{1}$ Research was supported by State and Federal funds appropriated to the Ohio Agricultural and Development Center, The Ohio State University.

${ }^{2}$ Corresponding author: eastridge.1@osu.edu
}

studying the biohydrogenation (BH) of FA from fresh plants. After harvesting, loss of lipids in forages occurs due to oxidation of unsaturated fatty acids (UFA) through the activity of plant lipases (Fried, 1993) and lipoxygenases (Gardner, 1991), decreasing the amount of UFA (Dewhurst et al., 2002). The 18:2 and 18:3 FA from plant tissues are the primary target of plant lipases (Fried, 1993), and are broken down even further to volatile organic compounds that cannot be used by the animals as a source of energy. Therefore, organic solvents used to extract FA from fresh forages should be able to inhibit plant lipases and quantitatively extract the FA from the plant matrix.

Most commonly used solvents for lipid extraction from fresh tissues are based on mixtures of chloroform and methanol (Folch et al., 1957; Bligh and Dyer, 1959). However, the chloroform:methanol procedures have suffered criticism regarding their wash step and loss of some lipid classes (Nelson, 1991). Hexane:isopropanol (H:IP; 3:2, vol/vol) can be used as an alternative solvent to extract lipids from biological matrices because it is less toxic, extracts less nonlipid fraction, and offers simpler handling procedures (Hara and Radin, 1978; Radin, 1981). Furthermore, IP inhibits loss of UFA resulting from enzymatic peroxidation by plant enzymes (Fried, 1993).

Quantitative analysis of total FA is time consuming and consists of combining sequential extractions from each sample; an alternative approach is to correct for the amount of total FA recovered in the first extraction after the method has been validated. However, we were not aware of any study evaluating the profile of FA from individual extracts using H:IP. Therefore, our objective was to test the hypothesis that the number of extractions using H:IP (3:2, vol/vol) will alter the profile of FA from fresh alfalfa.

Alfalfa samples (prebloom/bloom) were obtained from a greenhouse at the Ohio Agricultural Research and Development Center (Wooster, OH). Eight samples were harvested randomly on the same day and immersed immediately in liquid nitrogen using a metal grid. Samples were weighed and immersed in H:IP for 2 min and stored at $8^{\circ} \mathrm{C}$ in the dark until extraction. Separate samples were used to determine DM (6 h at 
Table 1. Proportion of fatty acids extracted from fresh alfalfa using hexane:isopropanol

\begin{tabular}{|c|c|c|c|c|c|}
\hline \multirow[b]{2}{*}{ Fatty acids } & \multicolumn{3}{|c|}{ Extraction no. } & \multirow[b]{2}{*}{ SEM } & \multirow[b]{2}{*}{$P$-value } \\
\hline & 1 & 2 & 3 & & \\
\hline & \multicolumn{5}{|c|}{ - (\% of fatty acids recovered among extractions $)-$} \\
\hline Total fatty acids & $92.7^{\mathrm{a}}$ & $4.8^{\mathrm{b}}$ & $2.6^{\mathrm{b}}$ & 1.7 & $<0.01$ \\
\hline $16: 0$ & $92.3^{\mathrm{a}}$ & $4.3^{\mathrm{b}}$ & $3.4^{\mathrm{b}}$ & 1.5 & $<0.01$ \\
\hline $18: 0$ & $93.7^{\mathrm{a}}$ & $4.0^{\mathrm{b}}$ & $1.6^{\mathrm{b}}$ & 2.0 & $<0.01$ \\
\hline $18: 1$ & $94.0^{\mathrm{a}}$ & $3.8^{\mathrm{b}}$ & $2.2^{\mathrm{b}}$ & 1.6 & $<0.01$ \\
\hline $18: 2$ & $93.6^{\mathrm{a}}$ & $4.5^{\mathrm{b}}$ & $2.6^{\mathrm{b}}$ & 1.8 & $<0.01$ \\
\hline \multirow[t]{2}{*}{ 18:3 } & $96.0^{\mathrm{a}}$ & $2.9^{\mathrm{b}}$ & $1.3^{\mathrm{b}}$ & 2.0 & $<0.01$ \\
\hline & \multicolumn{5}{|c|}{ - $(\%$ of total fatty acids within each extraction $)-$} \\
\hline 16:0 & 26.6 & 22.3 & 20.8 & 6.56 & 0.63 \\
\hline $18: 0$ & 4.9 & 3.8 & 6.1 & 1.53 & 0.37 \\
\hline $18: 1$ & 2.5 & 1.8 & 1.7 & 0.52 & 0.36 \\
\hline $18: 2$ & 7.0 & 5.6 & 5.8 & 0.58 & 0.20 \\
\hline $18: 3$ & $47.7^{\mathrm{a}}$ & $27.0^{\mathrm{b}}$ & $18.1^{\mathrm{b}}$ & 6.37 & 0.01 \\
\hline Saturated:unsaturated & $0.67^{\mathrm{a}}$ & $2.28^{\mathrm{b}}$ & $3.46^{\mathrm{b}}$ & 0.84 & 0.05 \\
\hline 16:0/18:3 & $0.58^{\mathrm{a}}$ & $0.88^{\mathrm{a}}$ & $1.63^{\mathrm{b}}$ & 0.17 & $<0.01$ \\
\hline
\end{tabular}

${ }^{\mathrm{a}, \mathrm{b}}$ Least squares means within a row with different superscripts $\operatorname{differ}(P<0.05)$.

$105^{\circ} \mathrm{C}$ ). Additionally, another 8 alfalfa samples were harvested and frozen as described above, and the leaves and stems were separated for determining FA composition.

Samples were extracted 3 times and each extract was analyzed separately. For the first extraction, approximately $5 \mathrm{~g}$ of the frozen alfalfa was mixed with $18 \mathrm{~mL}$ of H:IP per gram of material (Radin, 1981). Bottles containing original samples and solvent were put in ice and homogenized until totally fragmented. Samples were then centrifuged for $10 \mathrm{~min}$ at $10,000 \times g$, the supernatant was collected in a volumetric flask, and the solvent was evaporated, being careful to avoid total dryness. The second and third extractions were done by adding $\mathrm{H}: \mathrm{IP}$ to the pellet $(3 \mathrm{~mL} / \mathrm{g}$ of the original sample weight), mixing for $2 \mathrm{~min}$, and then centrifuging for $10 \mathrm{~min}$ at $10,000 \times \mathrm{g}$. Samples were maintained immersed in solvent at all times and kept in the dark at low temperature when possible.

Methylation of FA from the concentrated extracts was performed as described by Sukhija and Palmquist (1988) with some modifications. Two milliliters of benzene containing $17: 0$ acid $(2 \mathrm{mg} / \mathrm{ml})$ and $3 \mathrm{~mL}$ of $10 \%$ $\mathrm{HCl}$ were added to each tube. Fatty acid methyl esters were analyzed by GLC (model 5890; Hewlett-Packard, Palo Alto, CA) using a $30 \mathrm{~m} \times 0.25 \mathrm{~mm}$ i.d., $0.2-\mu \mathrm{m}$ film thickness SP-2380 fused silica capillary column (Supelco, Bellefonte, PA). This system was coupled to a mass spectrometer (Thermo Finnigan Trace 2000) and a data system (Xcalibur 2000; Thermo Finnigan, San Jose, CA). Nitrogen was used as the carrier gas. Detector and injector temperatures were set at 250 and $220^{\circ} \mathrm{C}$, respectively, and the split ratio was set at 100:1. Oven temperature was set for $160^{\circ} \mathrm{C}$ for $10 \mathrm{~min}$, increased by $3.0^{\circ} \mathrm{C} / \mathrm{min}$ to $180^{\circ} \mathrm{C}$ and held for $60 \mathrm{~min}$, increased by $5.0^{\circ} \mathrm{C} / \mathrm{min}$ to $220^{\circ} \mathrm{C}$ and held for $50 \mathrm{~min}$, and decreased by $20^{\circ} \mathrm{C} / \mathrm{min}$ to $160^{\circ} \mathrm{C}$ for $1 \mathrm{~min}$.

Data were analyzed as a randomized complete block design with repeated measures in space (all 3 extractions applied to the original sample) using the mixed models procedure of SAS (SAS Institute, 2004). Protected Fisher's LSD test was used to compare treatment means. Significance was declared at $P<0.05$.

Because lipids are associated with polar compounds to form biological membranes, solvents used to extract fatty acids from animal and plant tissues must have a combination of polar and nonpolar solvents. The H:IP solvent was used, as an alternative to more toxic and most frequently used solvents (Folch et al., 1957; Bligh and Dyer, 1959) to quantitatively extract FA from plant tissues. The use of $\mathrm{H}$ :IP as a solvent system to quantitatively extract FA from fresh forages has a few advantages over chloroform:methanol; IP helps to inhibit enzymatic activity and loss of FA (Fried, 1993), and IP and hexane are less toxic than methanol and chloroform, respectively (Nelson, 1991).

The mass spectrometer was used to detect artifacts that may be produced during the extraction/methylation procedure. Trace amounts of isopropyl esters (data not shown) were detected in the samples; their origin may be either from the plant tissues or synthesis during the methylation step or both.

The percentage of total FA from the alfalfa samples averaged $4.0 \%$, with about $65 \%$ of the FA in leaves and $35 \%$ in stems (data not shown). Repeated extractions increased $(P<0.01)$ the percentage of total FA recovered from the samples (Table 1). The values for total FA for the first, second, and third extractions were 92.7, 4.8, and $2.6 \%$ of the total, respectively. There was no difference $(P>0.05)$ in the percentage of $16: 0,18: 0,18: 1$, 
and 18:2 among extractions. However, the first extract contained a higher percentage of 18:3 $(P<0.01)$ compared with extractions 2 and 3 , and a lower ratio 16:0 to $18: 3(P<0.05)$ compared with extraction 3 . This ratio is more sensitive in showing loss of FA because 18:3 is more prone to oxidation than the other FA reported, whereas 16:0 should not vary. Also, the ratio of saturated to unsaturated FA increased $(P=0.05)$ from the first to the second extraction. The percentage of FA not reported in Table 1 (mostly saturated long-chain FA) increased from the first to the third extraction (data not shown), with these saturated FA accounting for about $48 \%$ of total FA in the last extraction. However, these FA only represented approximately $0.05 \%$ of the sample DM or $2.5 \mathrm{mg}$ of FA in the $5 \mathrm{~g}$ of forage sampled.

The percentage of FA extracted from the first extraction (92.7\%) could be used as a correction factor to quantify FA from fresh alfalfa in future experiments using the same methodology and just one extraction, while adjusting for 18:3 as well. We observed that the leaves contained $76 \%$ of total 18:3. Most of the plant FA is concentrated in the chloroplasts; 18:3 is the major FA in plant tissue, constituting about 75 to $95 \%$ of FA from galactolipids in alfalfa leaf tissue (Hawke, 1973). The greater value for 18:3 in the first extract reflects the greater proportion of 18:3 in the more easily extracted plant fraction and also show that H:IP is a solvent able to quantitatively extract phospholipids and galactolipids (more polar molecules), triglycerides, and FA. This characteristic is essential when studying FA esters from biological membranes.

Because $\mathrm{BH}$ occurs with UFA, preserving their proportion in the samples to be studied is critical; the concentration of UFA in the samples affects the rate of synthesis of intermediates of the $\mathrm{BH}$ and also their concentration in the rumen fluid. Research evaluating the $\mathrm{BH}$ of $\mathrm{FA}$ from fresh forages must prioritize efforts to minimize loss of FA after harvesting. Moreover, the loss of leaves during wilting decreases the proportion of UFA and total FA. Thus, we adopted the use of H:IP as a solvent to extract and inhibit loss of FA from fresh alfalfa.

The percentage of 18:3 in fresh alfalfa decreased with an increasing number of extractions and, therefore, changed the ratio of saturated FA to UFA. No difference was observed for the other FA. More than one extraction is recommended for determining the amount and profile of individual FA in fresh forages. Each laboratory should evaluate the profile and percentage of total FA from each extraction before using a single extraction to predict them.

\section{REFERENCES}

Bligh, E. G., and W. J. Dyer. 1959. A rapid method of total lipid extraction and purification. Can. J. Biochem. Physiol. 37:911-917.

Dewhurst, R. J., J. M. Moorby, N. D. Scollan, J. K. S. Tweed, and M. O. Humphreys. 2002. Effects of a stay-green trait on the concentrations and stability of fatty acids in perennial ryegrass. Grass Forage Sci. 57:360-366.

Folch, J., M. Lees, and G. H. Sloane Stanley. 1957. A simple method for the isolation and purification of total lipids from animal tissues. J. Biol. Chem. 226:497-509.

Fried, B. 1993. Obtaining and handling biological materials and prefractionating extracts for lipid analysis. Pages 1-10 in Analysis of Lipids. K. D. Kumar and N. Weber, ed. CRC Press, Inc., Boca Raton, FL.

Gardner, H. W. 1991. Recent investigations into the lipoxygenase pathway of plants. Biochim. Biophys. Acta 1084:221-239.

Hara, A., and N. S. Radin. 1978. Lipid extraction of tissues with a low-toxic solvent. Anal. Chem. 90:420-426.

Hawke, J. C. 1973. Chemistry and biochemistry of herbage. Pages 213-263 in Lipids. G. W. Butler and R. W. Bailey, ed. Academic Press, London, UK.

Nelson, G. J. 1991. Isolation and purification of lipids from biological matrices. Pages 20-59 in Analyses of fats, oils and lipoproteins. E. G. Perkins, ed. American Oil Chemists' Society, Champaign, IL.

Radin, N. S. 1981. Extraction of tissue lipids with a solvent of low toxicity. Methods Enzymol. 72:5-7.

SAS Institute. 2004. SAS/STAT User's Guide. Version 8 ed. SAS Institute Inc, Cary, NC.

Sukhija, P. S., and D. L. Palmquist. 1988. Rapid method for determination of total fatty acid content and composition of feedstuffs and feces. J. Agric. Food Chem. 36:1202-1206. 